NOTICE: This is the author's version of a work that was accepted for publication in Applied Energy. Changes resulting from the publishing process, such as peer review, editing, corrections, structural formatting, and other quality control mechanisms may not be reflected in this document. Changes may have been made to this work since it was submitted for publication. A definitive version was subsequently published in Applied Energy, Vol. 113 (2014).

http://doi.org/10.1016/..apenergy.2013.07.048 


\title{
The Role of Natural Gas in a Low Carbon Asia Pacific
}

\author{
Roberto F. Aguilera ${ }^{a}$
}

\begin{abstract}
As the Asia Pacific region continues to experience rapid economic growth, natural gas may have an important role in satisfying regional demand and transitioning to a low carbon economy. In this study, a Global Energy Market Model (GEM) is used to analyze the market shares of gases, liquids and solids in the Asia Pacific. The model matches the historical energy mix from 1850 to 2010 as well as the historical hydrogen to carbon $(\mathrm{H} / \mathrm{C})$ ratio. The GEM is then used to present scenarios of the Asia Pacific energy mix and $\mathrm{H} / \mathrm{C}$ ratio to the year 2030. The scenarios vary according to policies and technologies that either encourage or discourage gas use. Estimates of conventional and unconventional gas quantities and costs are also presented, partly with a Variable Shape Distribution Model (VSD) and supply curves. The Asia Pacific is found to have vast natural gas resources, though suitable policies are needed to develop the potential. For instance, incentives will be necessary for investment in gas and LNG technology, as increased market share will not occur if investment does not take place in a timely fashion. In addition, it is important that government intervention not create disincentives for development of the regional gas and LNG industries.
\end{abstract}

Keywords: conventional and unconventional natural gas; Asia Pacific; energy mix; supply curves

\footnotetext{
${ }^{a}$ Centre for Research in Energy and Minerals Economics (CREME), Curtin University, GPO Box 1987, Perth WA 6845, Australia, Phone: 618-9266-9137, Email: r.aguilera@ curtin.edu.au
} 


\section{INTRODUCTION}

2

3 In the Asia Pacific, economic growth has mostly been fueled by coal and to a lesser extent oil. However, the importance of natural gas is expected to increase dramatically. This has the potential to bring benefits related to energy security and the environment if the region enacts policies that allow for setting national and international contracts for the provision of natural gas. Unlike North America, where most gas is sold under arrangements that include a pricing mechanism tied to the price of gas quoted at Henry Hub, Louisiana, natural gas pricing in the Asia Pacific has historically been tied contractually to crude oil. It is only recently that alternatives have been introduced as increased spot cargoes arrive from other regions. There is the possibility of decreased gas prices in the Asia Pacific as additional supply is introduced from North American liquefied natural gas (LNG) exports. Furthermore, when assessing the potential conventional and unconventional resources of the Asia Pacific, there appears to be sufficient natural gas to satisfy even the most optimistic of regional demand estimates. Depending on the rate of development of these resources, the available volumes will have further implications for the regional pricing mechanisms that will evolve. The dampening effect on prices should lead to increased consumption and the associated benefits of natural gas use. However, several obstacles must be overcome in order to reap the benefits from natural gas use. Some of these include limited gas delivery infrastructure, lack of competition and transparency, high transportation costs, lack of storage facilities, underdeveloped and inflexible markets, and limited legal and regulatory frameworks.

To address the issue of physical availability, [1] use a VSD model to show there is no conceivable shortage of conventional gas in the Asia Pacific. Furthermore, unconventional gas resources are shown to be significantly more abundant than their conventional counterparts. However, it is important to note that the vast resources do not provide energy 
1 services unless they are first converted to reserves, which are a function of technical,

2 commercial, and institutional conditions. To assess the economic availability of natural gas in

3 the region, supply curves showing production costs versus quantities are estimated.

5 Figure 1 shows the regional population and income, which has been increasing exponentially

6 since 1965, as well as historical and projected future energy consumption. The upper curve is

7 actual Asia Pacific primary energy consumption per year [2]. Since 1965, the average increase in total energy consumption has been in the order of $10.9 \%$ per year. Presently, there is rapid demand growth and it is estimated that energy consumption per capita will rise to approximately 80 million BTU per year by 2030 (middle curve, Figure 1). The lower curve shows the actual Asia Pacific population from 1965 to the present and a forecast to 2030 [3].

This extrapolation gives a figure of about five billion people by 2030 .

\section{MATERIAL AND METHODS}

\subsection{GLOBAL ENERGY MARKET MODEL (GEM)} later used by [6]: 
$1 \quad y=\frac{f}{1-f}=\exp (\alpha t+\beta)$

3 Where:

$4 \quad f$ is market share;

$5 t$ is time;

$6 \quad \alpha$ is a slope parameter;

$7 \quad \beta$ is an intercept parameter;

8

9 The Fisher and Pry model says that if $y=f /(1-f)$, a semi-logarithmic graph of $y$ versus time will give a straight line of slope $\alpha$ and intercept $\beta$. This standard model gives a good match of

11 historical market shares from 1850 to 1970 (Figure 2). After 1970, the data deviates from the model, due to intensive coal use that captured increased market share in the Asia Pacific after the oil crises of the 1970 s.

14

We alter equation 1 to include the effects of deviation from a straight line [4]. As presented in equation 2, the GEM model is used to calculate the market fraction of an energy source that is declining with time (e.g. solids):

$$
y_{G E M}=\frac{\exp (\alpha t+\beta)}{\psi+(1-\psi)\left[1-\exp \left(-y / y_{s}\right)\right]^{S}}=\frac{f}{1-f}
$$

Where:

$Y_{G E M}$ is the altered linear function;

$\alpha$ and $\beta$ are defined above for the Fisher and Pry model;

$t$ is time; 
$1 \psi$ represents the approximate point at which a shifted straight line is developed;

$2 y_{s}$ controls the deviation from the straight line;

$3 \quad S$ is a severity exponent that controls the slope of the curve deviating from the straight line;

$4 y$ is the logistic substitution function presented in equation 1.

5

6 Rearranging the left and right hand sides of equation 2 gives:

$$
f=\frac{y_{G E M}}{1+y_{G E M}}
$$

For an energy source with a market fraction that is increasing with time (e.g. gases), the numerator in equation 1 is multiplied by $\psi$. The parameters for the declining and increasing market shares are not the same and have to be determined independently. The liquids' fraction is calculated as the difference between 1.0 and the summation of the solids and gases fractions.

\subsection{VARIABLE SHAPE DISTRIBUTION MODEL (VSD)} used to estimate oil and gas quantities were "based on an assumed form of the size-frequency distribution of the natural population of oil and gas accumulations" [7]. The lognormal and Pareto (fractal) distributions are traditional distributions used to estimate volumes in unassessed areas. Several experts have found that a lognormal distribution best represents 
1 pessimistic results [9]. In general, it has been proved that the Pareto distribution

2 overestimates resources and the lognormal distribution underestimates them.

3

4 The VSD is different because it starts by observing the curvature displayed on log-log 5 coordinates of the assessed provinces in the United States Geological Survey (USGS) World

6 Petroleum Assessment 2000 [10]. The VSD model does not assume a distribution ex ante;

7 rather, the relationship between the number and size of provinces is defined by the data itself.

8 The initial close match means the model can be extended out of sample to include provinces

9 not previously assessed. The assessed provinces are typically the largest, meaning the

10 previously unassessed provinces tend to be smaller volumetrically. [11].

The VSD function is given as:

$$
\min \operatorname{n}_{\left\{V_{x}, a_{p}, V_{S}, \psi, S\right\}} \sum_{i=1}^{n}\left(V_{i}-\hat{V}_{i}\right)^{2}
$$

Subject to:

$$
\hat{V}_{i}=\frac{\left\{\left[\left(\frac{1}{N_{t}}-\left(\frac{V_{m}}{V_{x}}\right)^{\frac{\log N_{x}-\log N_{m}}{\log V_{x}-\log V_{m}}}\right)^{\frac{1}{a_{p}}}+\frac{V_{m}}{V_{x}}\right] \cdot V_{x}\right\} \cdot(\psi)}{\left.(\psi)+[1-(\psi)] \cdot\left[1-\exp \left(-\left\{\left[\left(\frac{1}{N_{t}}-\left(\frac{V_{m}}{V_{x}}\right)^{\left(\frac{\log N_{x}-\log N_{m}}{\log V_{x}-\log V_{m}}\right)}\right)^{\frac{1}{a_{p}}}+\frac{V_{m}}{V_{x}}\right] \cdot V_{x}\right\} \cdot V_{s}^{-1}\right)\right]\right]^{S}}
$$

20 Where:

$21 a_{p}$ - slope of Pareto line approximated from largest USGS sample points.

$N_{m}$ - minimum number of provinces $(=1)$. 
$1 \quad N_{t}$ - cumulative number of provinces.

$2 \quad N_{x}$ - maximum number of provinces.

$3 \quad S$ - severity exponent controlling the slope of the VSD curve where it deviates from the

4 straight line.

$5 \quad V_{m}$ - minimum province volume.

$6 \quad V_{s}$ - approximate volume where the USGS data deviates from the Pareto line.

$7 \quad V_{i}$ - observed province volume.

$8 \quad \hat{V}_{i}$ - estimated province volume.

$9 \quad V_{x}$ - maximum volume given by the Pareto line.

$10 \psi$ - separation ratio controlling the separation between the Pareto line and the VSD curve.

12 The parameter values are estimated based on visual comparison of the curves, maximization 13 of the coefficient of determination $\left(\mathrm{R}^{2}\right)$, and similarity of the volumes.

\subsection{SUPPLY CURVES}

17 Once the natural gas volumes are estimated, we proceed to develop supply curves. This 18 involves distributing the conventional natural gas quantities across five categories, each 19 defined by a range of production costs. The resulting curve further includes unconventional gas by adopting quantities from [12] and attaching production costs based on [13]. A second supply cost curve is estimated by incorporating the effects of technological progress to the year 2030. Progress at rates between $0.75 \%$ and $1.25 \%$ per year are used to project the 2030 costs. According to [14], historical rates have been around $1 \%$. 
1 Table 1 shows production costs per thousand cubic feet (MCF) in 2010 USD, the assumed

2 rates of technological improvement per year for each category, and the production costs for

3 2030. Improvements in technology are larger in the first three categories where production

4 conditions are more benign.

Table 1

Fluctuating growth year after year makes productivity estimates very uncertain $[15,16]$.

Therefore, the presented rates may be overly optimistic or pessimistic.

The distribution of conventional gas across categories is assumed to be $30 \%$ for CI, $35 \%$ for CII, 20\% for CIII, $10 \%$ for CIV, and 5\% for CV [17]. Unconventional sources are accounted for in the bottom half of Table 1, with average cost estimates given for each source. The 2010 cost estimates are based on [13], while the annual technological improvement is assumed to be the same as category CV. 


\section{RESULTS}

3

4 Figure 2 shows the reference case actual and calculated fractional contributions to the market

5 given by solids, liquids and gases from 1850 to 2030. The solids-liquids-gases concept was

6 introduced originally by [18]. Solids include wood, traditional renewables, coal and uranium.

7 Liquids include oil and hydropower, and gases include initially methane, and later wind,

8 solar, and hydrogen. Similar combinations are used in this study, however, there are alternate

9 ways of examining the mix. The GEM model, as with the Fisher-Pry model, can also be used

10 to analyze individual energy sources - e.g. coal and uranium, separately, in order to reflect

11 shifts from coal based power to nuclear based power. The same holds true for individual

12 liquid or gas sources. However, data limitations exist for certain resources in the Asia Pacific.

For the case of solids, the calculated curve was generated using the following parameters: $\alpha=$ $-0.0625, \beta=7.4, \psi=0.02, y_{s}=0.35$ and $S=1.9$. For the gases, the calculated curve was generated with the following parameters: $\alpha=0.0975, \beta=15.4, \psi=0.024, y_{s}=3.95$ and $S=$

1.14. While the parameter values do not carry particular economic, policy, or technological meaning, they serve to match the actual historical data and project future scenarios of the energy mix.

The comparison between actual and calculated values is very close, as confirmed by the $\mathrm{R}^{2}$ equal to 0.98 . This gives us confidence that our energy mix scenarios are reasonable. The GEM model reference case specifies that by the year 2030, around $46 \%$ of primary energy in the Asia Pacific will be provided by solids, $34 \%$ by liquids, and $20 \%$ by gases. 
1 It is important to recognize that a good fit of the past is not necessarily a good indicator of the

2 future. Furthermore, non-uniqueness is a basic part of any history matching procedure.

3 Uncertainty and non-ergodicity, discussed in [19] as it relates to economic change, make it very complex to predict long-term energy outcomes. As a result, we attempt to address these issues with some alternative cases, as shown in Figures 3 and 4. In the first alternative case

6 (Figure 3) there is a significant increase in the contribution of solids, and a decrease in 7 liquids, to the energy mix. The gas share increases very slightly. In the second alternative case (Figure 4) there is a slight decrease in the contribution of solids and a slower reduction of liquids. In this case, the gas share increases significantly.

Once the energy mix scenarios are developed, it is important to assess whether there is sufficient natural gas in the Asia Pacific to satisfy those projections. The response is affirmative based on research carried out with the VSD model [1]. The model was validated by comparing calculated and actual natural gas volumes presented by [10]. 5). For more details on reserve growth, refer to [1].

Unconventional gas volumes - composed of tight gas sands, CBM and shale gas - are taken 
1 and environmental obstacles can be overcome. Shale gas is the most abundant (2530 TCFG),

2 followed by tight gas (2249 TCFG) and CBM (1970 TCFG).

3

4 The hydrogen over carbon (H/C) ratio, which can be used to represent environmental quality, has been used to calculate the Asia Pacific H/C ratio shown in Figure 7. The calculation uses the fractions of wood, coal, oil and gas (starting in 1900), and the average $\mathrm{H} / \mathrm{C}$ ratios: 0.10 for wood, 0.5 for coal, 2.0 for oil, and 4.0 for gas. Each ratio is weighted with the actual and GEM-calculated fractional contributions of wood, coal, oil and gas. The middle curve corresponds to the reference case, while the lower and upper curves correspond to alternative cases 1 and 2, respectively.

Figure 7 shows uninterrupted decarbonization from 1900 to 1970, at which point the H/C ratio flattens. This is likely the result of government interventions such as gas price regulations that lead to decreased gas consumption and increased coal consumption. Those regulations would make the economics of coal production favorable relative to that of natural

\section{DISCUSSION}

The significance of natural gas in the future energy mix will depend to a large extent on energy policy. As the Asia Pacific will experience the largest amount of energy growth in the world, the policies enacted in this region will have far-reaching consequences. Complex and artificial pricing mechanisms are likely to discourage investment and thus hinder the penetration of gas into the energy market. Government policies that limit foreign investment 
1 (e.g. excessively high taxes and royalties) will also inhibit the contribution of gas to the

2 energy mix. In spite of the evolving market structure discussed earlier, prices in the Asia

3 Pacific are locked into long term contracts and delinking from oil could be time-consuming and complex. Even though it would be possible to see elements of $\mathrm{HH}$ pricing co-existing with other price mechanisms, it is not entirely certain that consuming nations would prefer this. For instance, [20] emphasize that hub-based pricing will not unambiguously lead to natural gas prices that are lower than those currently based on crude oil or other oil products. The hub-based, gas-on-gas prices will be determined by the relative balance of supply and demand for natural gas, which may at times be tight and thus lead to high prices. At the same time, the oil markets may be relatively loose, producing low oil prices that would indicate lower oil-based natural gas prices. According to [21], Asian buyers are unlikely to want to be overly exposed to variations unlinked to their own markets. Thus, they may want to protect the existing price mechanism in spite of the higher expected prices. Producing nations within the Asia Pacific might also prefer this as it is more likely to ensure the commercial viability of their LNG and pipeline projects.

Over the past decade, LNG has reached the Asian market from a wide range of producing regions. Demand has also spread beyond Japan, the former dominant market, to Taiwan, South Korea, and China, with additional developments underway in several other countries in the region. Southeast Asia does not currently import LNG, but relies on pipeline trade. Increased consistency of regulatory and market regimes across southeast Asian nations should help spur investment in inter-regional pipeline infrastructure and encourage trade and competition. An attractive investment climate will also play a role in developing small-scale floating LNG technology, which is well-suited to the area [22]. 
1 Although natural gas is used primarily for electricity generation, there may be possibilities in

2 transportation if natural gas vehicles become more prevalent. Since relative prices and costs

3 determine the winners amongst competing fuels, taxes on carbon emissions are also likely to

4 favor gas instead of the more carbon-intensive fossil fuels (coal and oil). It is important to

5 note that - apart from energy policy - other economic, social, historical, and cultural factors

6 will too be important determinants of future energy outcomes.

8 With regard to the natural gas resource base in the Asia Pacific, both conventional and unconventional quantities are found to be abundant. Figure 5 shows VSD-generated curves that represent the conventional gas endowment in the region. The outer solid curve gives a total volume of 2240 trillion cubic feet. To put this into perspective, historical Asia Pacific cumulative gas production until 2010 was approximately 264 TCFG. For the unconventional gas (tight, CBM, shale), [12] gives a total endowment of 6749 TCFG.

The supply curves in Figure 6 show that the conventional and unconventional gas resources can be produced below market prices in the Asia region. As was the case in the past, technological progress is likely to decrease costs in the future.

\section{CONCLUSIONS}

A GEM model is used to assess the past, present and future of the Asia Pacific energy market. It is effective in matching the historical primary energy mix from 1850 to the present. In addition, the GEM provides a good match of the $\mathrm{H} / \mathrm{C}$ ratio (which represents environmental quality) from 1900 to the present. Scenarios of the fractional market shares of solids, liquids, and gases to 2030 suggest that the future of gases in the region could be promising. Policies would have to be enacted in order to favor capital investment in 
1 exploration and production, build distribution networks, develop integrated gas markets and easy means of transportation, and create transparent and competitive gas pricing mechanisms.

4 The GEM findings also indicate there could be potential for solids, but significant 5 technological advances will be required to make these environmentally viable (and safe in the 6 case of uranium/nuclear). In the GEM reference case, about $46 \%$ of the energy mix is 7 provided by solids, $34 \%$ by liquids and $20 \%$ by gases in 2030 . Since the past is not always a useful indication of the future, two alternative cases of the energy mix are generated.

A VSD model is also to estimate the conventional gas endowment in previously unevaluated Asia Pacific provinces. The VSD model is specified and validated with data from [10], which assesses volumes for 77 provinces out of a total of 290 . The model can then be used to estimate reasonable conventional gas volumes in all 290 provinces (estimated at 1437

TCFG). Reserve growth is found to further increase that volume to 2240 TCFG. With regard to unconventional gas, shale gas is the most abundant at $2530 \mathrm{TCFG}$, followed by tight gas at 2249 TCFG and CBM at 1970 TCFG.

Results of this study can be used to assess challenges and opportunities in the Asia Pacific as population, income, and energy demand continue to increase. An important conclusion is that there is enough natural gas to satisfy demand beyond the coming decades. For example, the conventional gas endowment alone - estimated at 2240 TCFG in 290 provinces - would last over 140 years assuming current annual consumption rates of about 15 TCFG [1]. If demand were to increase by $6 \%$ per year, as it has on average over the past 30 years, conventional gas would still last nearly 40 years. This presents significant prospects for governments and corporations who have the means and will to increase natural gas use. 
1 However, the existence of abundant gas alone will not guarantee security of supply. In order

2 to develop the vast resources, appropriate public policies are necessary. For instance,

3 investment in technology will be necessary to diminish production costs over time. Thus,

4 policies must provide incentives, and not create disincentives, for the development of gas

5 resources in the Asia Pacific.

6

[3] United Nations Population Division. World Population Prospects; 2010. http://esa.un.org/wpp/unpp/panel_population.htm (accessed 21 May 2013)

[4] Aguilera RF, Ripple RD. Modeling primary energy substitution in the Asia Pacific. Applied Energy 2013; forthcoming.

[5] Fisher JC, Pry RH. A simple solution model of technological change. Report 70_C-215. General Electric Company, Research and Development Center. New York; 1970.

[6] Marchetti C, Nakicenovic N. The dynamics of energy systems and the logistic substitution model. RR-79-13. International Institute for Applied Systems Analysis (IIASA) Publications. Laxenburg, Austria; 1979. 
[7] Barton CC. A new approach to estimating hydrocarbon resources. United States

Geological Survey Fact Sheet. Denver, Colorado; 1995.

http://webharvest.gov/peth04/20041016205020/http://energy.usgs.gov/factsheets/HydroRes/e

stimat.html

(accessed 21 May 2013)

[8] Kaufman GM. Where have we been? Where are we going? Natural Resources Research 2005; 14(3): 145-152.

[9] Drew LJ. Undiscovered petroleum and mineral resources - assessment and controversy.

Plenum Press, New York and London; 1997.

[10] United States Geological Survey. World Petroleum Assessment. CD-ROM, Virginia; 2000.

[11] Tangen G, Mølnvik MJ. Scenarios for remote gas production. Applied Energy 2009; 86 (12): 2681-2689.

[12] Global Energy Assessment. International Institute for Applied Systems Analysis

(IIASA). Cambridge University Press, United Kingdom; 2012.

[13] International Energy Agency. World Energy Outlook. Paris, France: Organization for Economic Cooperation and Development; 2009.

[14] Rogner HH. An assessment of world hydrocarbon resources. International Institute for Applied Systems Analysis (IIASA) Publications, RR-98-6. Also, Annual Review of Energy and Environment 1997; 22: 217-262.

[15] Adelman MA. The genie out of the bottle - world Oil since 1970. The MIT Press, Cambridge; 1995.

[16] Adelman MA. The economics of petroleum supply. The MIT Press, Cambridge; 1993.

[17] Aguilera RF, Eggert RG, Lagos G, Tilton JE. Depletion and the future availability of petroleum resources. Energy Journal 2009; 30 (1): 141-174.

[18] Hefner III RA. The age of energy gases in the new millennium. The GHK Company, Oklahoma; 2002. 
[19] North DC. Understanding the process of economic change. Princeton University Press, New Jersey; 2005.

[20] Stern R and H Rogers. The transition to hub-based gas pricing in continental Europe. The Oxford Institute for Energy Studies 2011; NG49, Oxford.

[21] LNG Business Review. Will US LNG exports upset the JCC linkage in Asian LNG contracts? LNG Business Review 2012; 5 (6): 4-9.

[22] International Energy Agency. Are we entering a golden age of gas? Paris, France: Organization for Economic Cooperation and Development; 2011. 


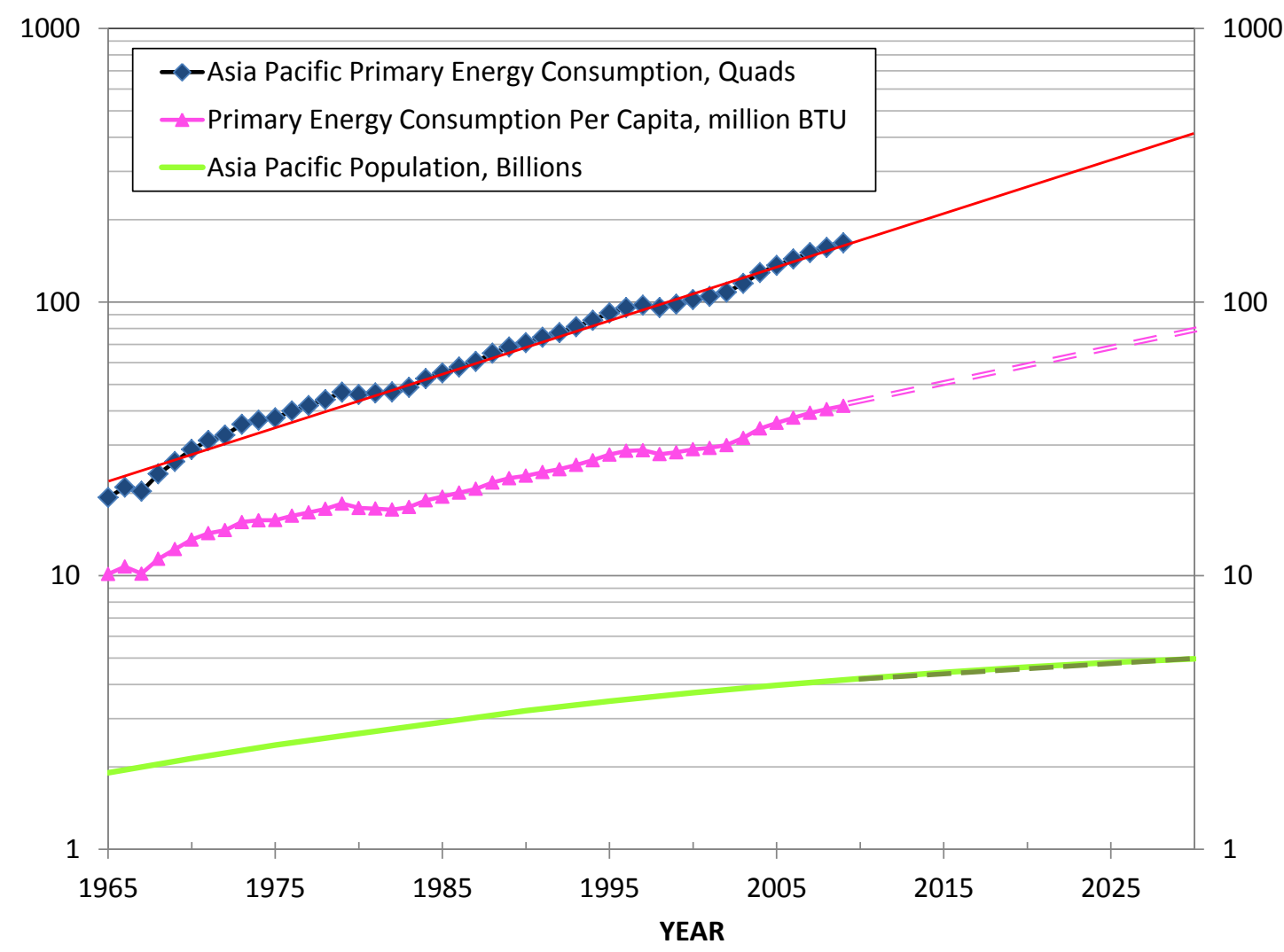

Fig. 1. Asia Pacific population and energy consumption.

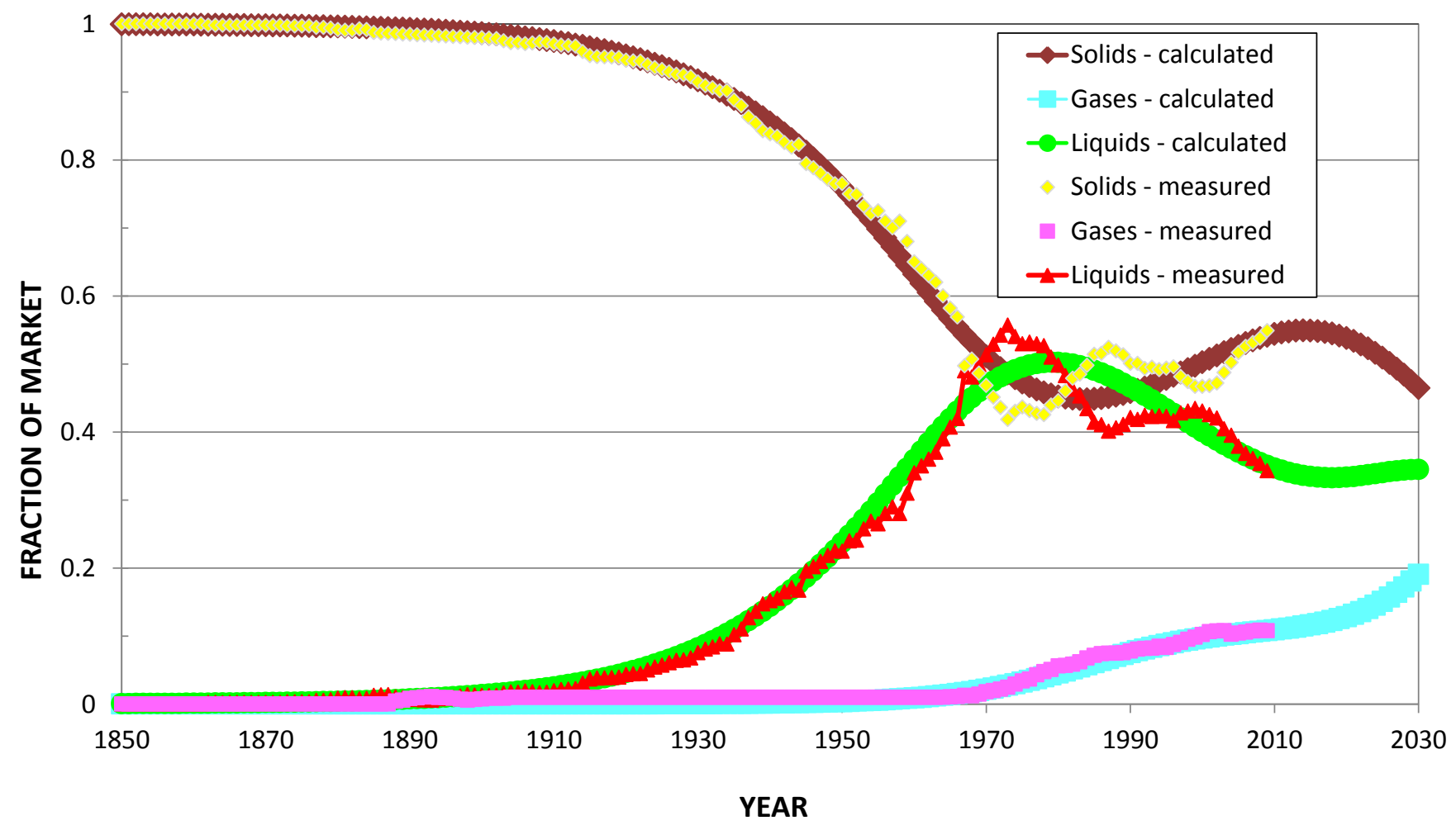

Fig. 2. Asia Pacific primary energy substitution curves - reference case from the GEM model. 


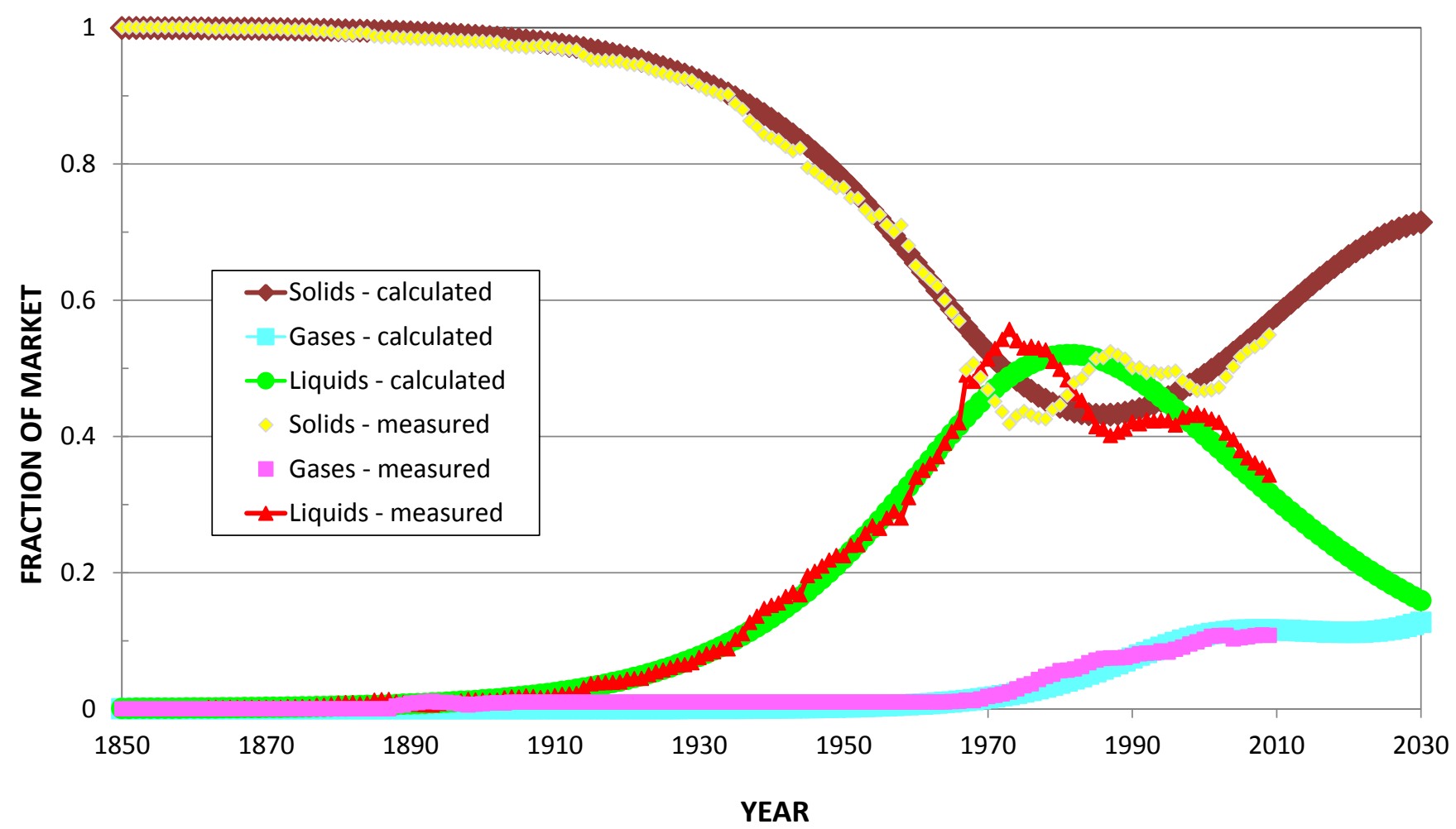

Fig. 3. Asia Pacific primary energy substitution curves - alternative case 1 from the GEM model.

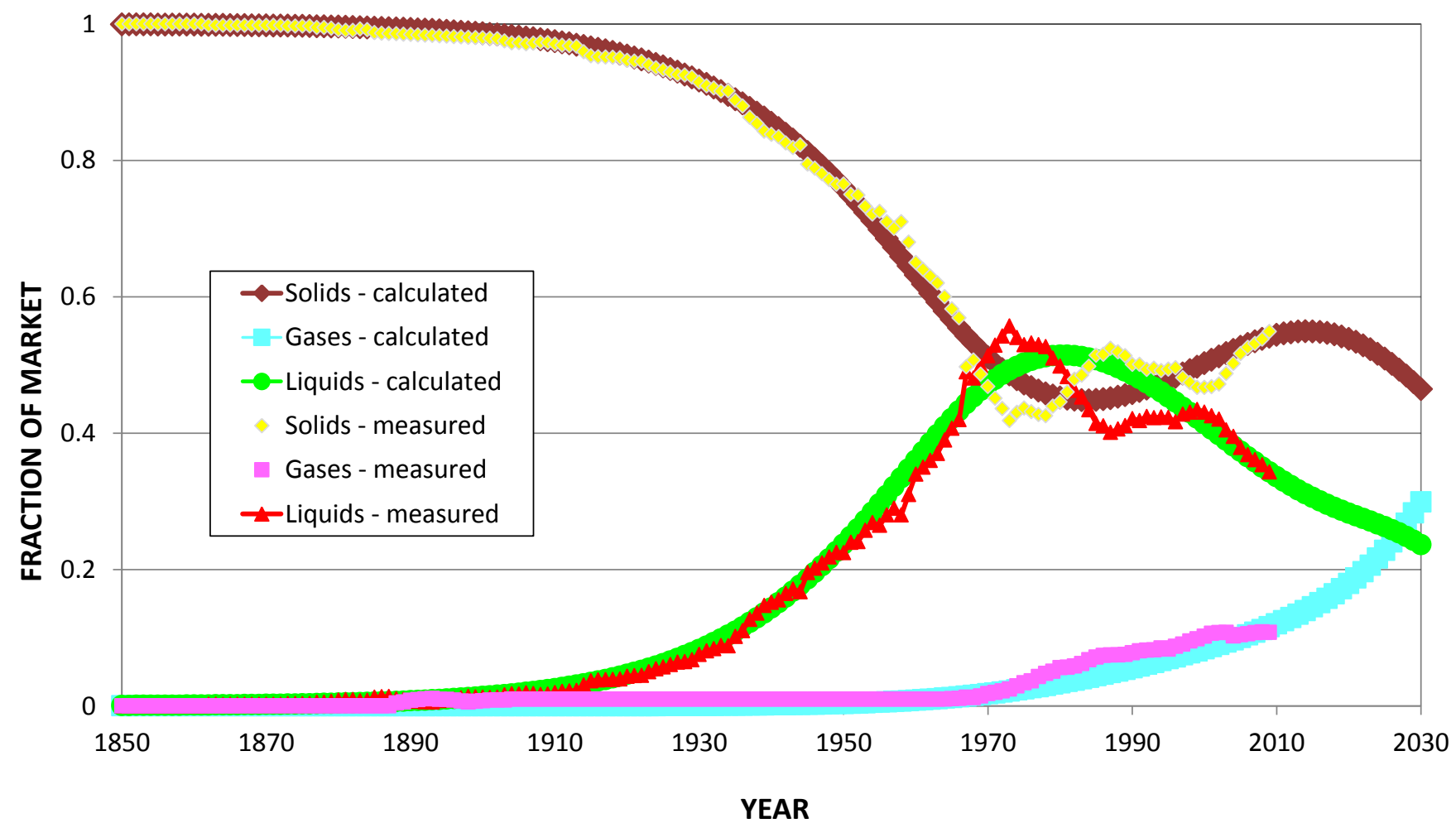

Fig. 4. Asia Pacific primary energy substitution curves - alternative case 2 from the GEM model. 


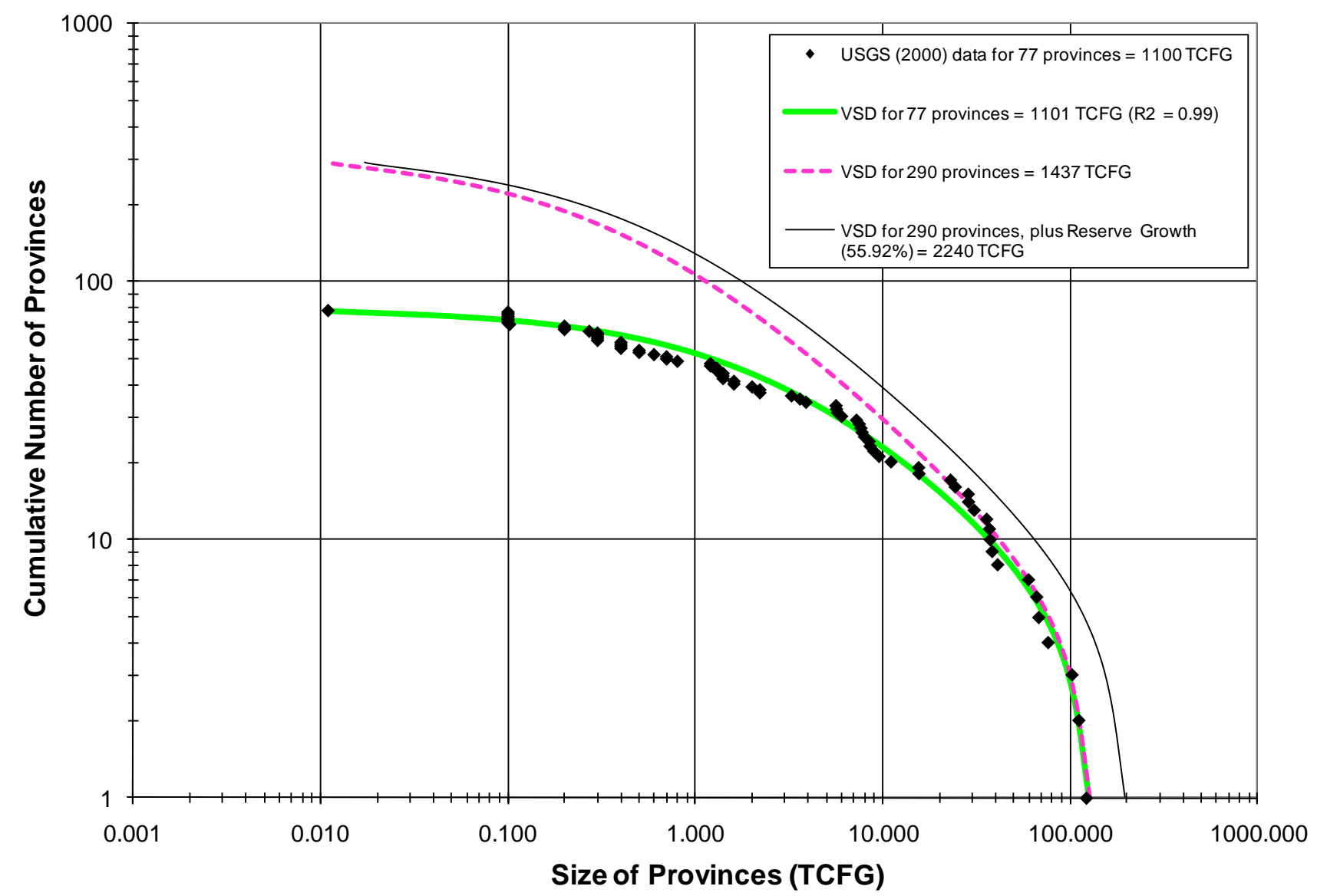

Fig. 5. VSD for Asia Pacific conventional gas endowment as estimated by [1] and [10]. 


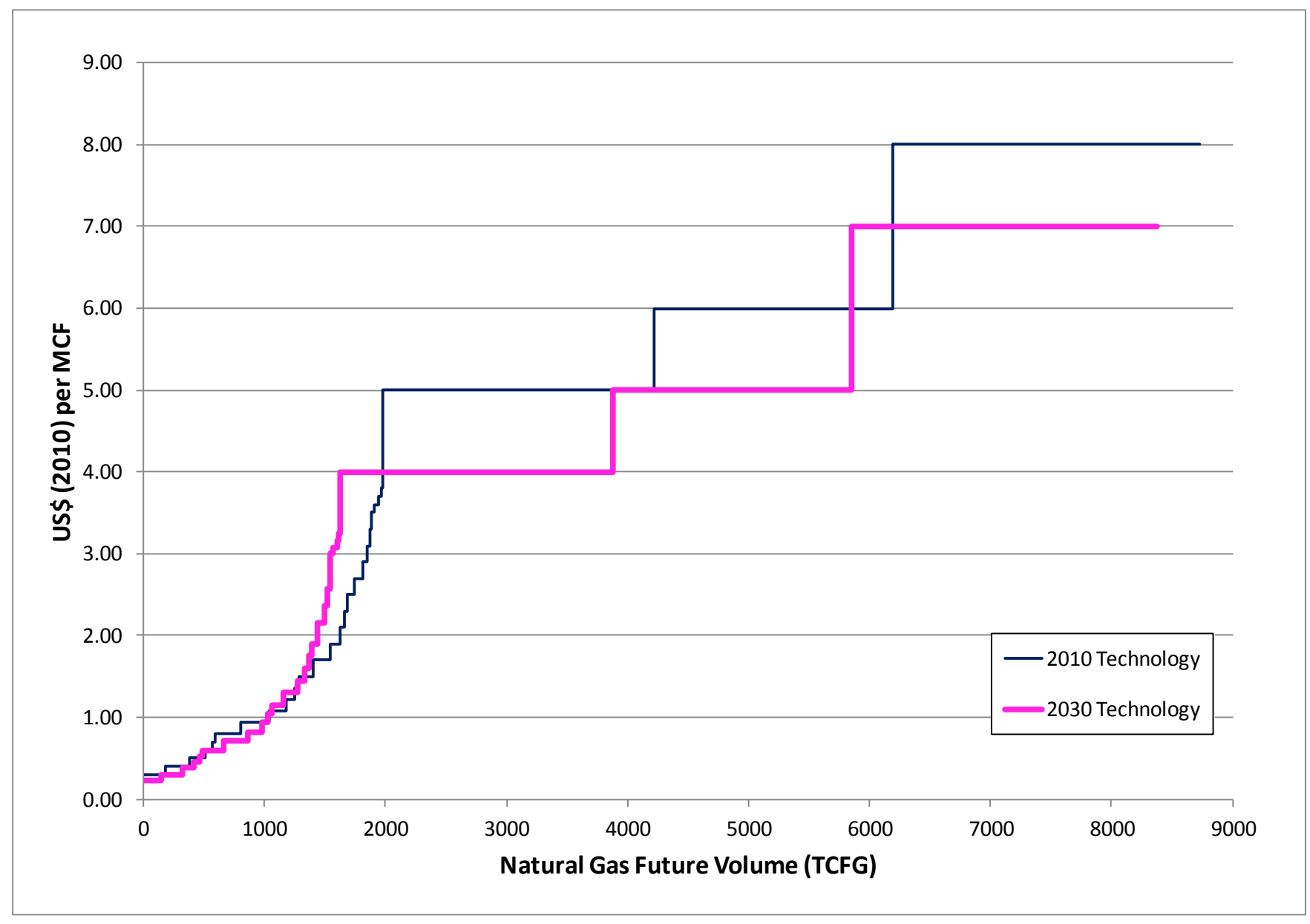

Fig. 6. 2010 and 2030 supply curves for conventional and unconventional gas in the Asia Pacific. 


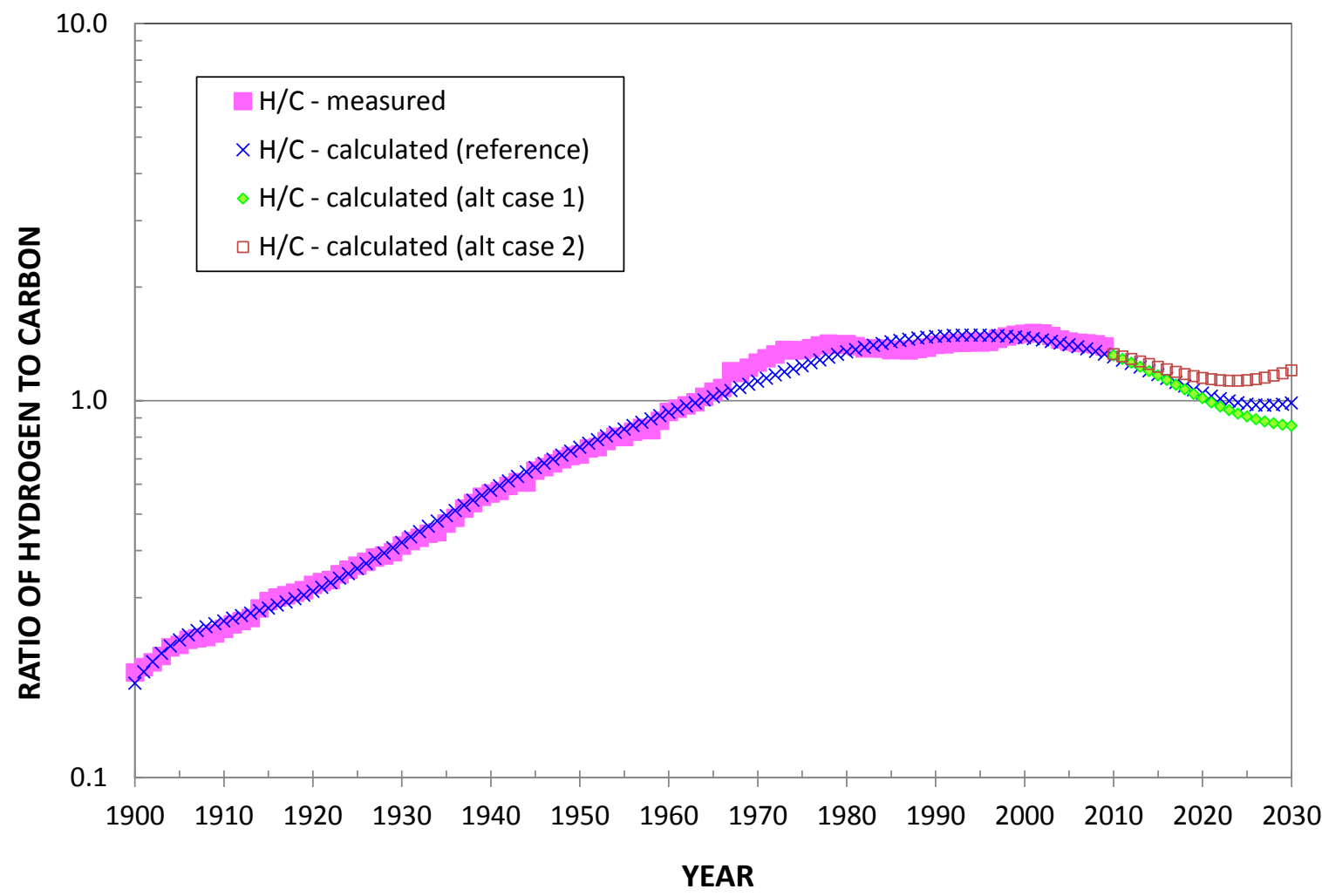

Fig. 7. Asia Pacific $\mathrm{H} / \mathrm{C}$ ratio representing environmental quality. 